\title{
Effect of Solvent Type and Drying Method on Protein Retention in Chitosan-Alginate Microcapsules
}

\section{Edith I Ahonkhai, Ikhuoria M Arhewoh and Augustine 0 Okhamafe}

Department of Pharmaceutics and Pharmaceutical Technology, Faculty of Pharmacy, University of Benin, Benin City 300001, Nigeria.

\begin{abstract}
Purpose: The effect of solvent used in dissolving chitosan (membrane material) and the microcapsule drying method used, on protein retention in chitosan-alginate microcapsules were studied since these factors affect the physicochemical characteristics of the coating membrane.

Method: The microcapsules were prepared by extruding a solution containing alginate and BSA into chitosan/calcium chloride solution prepared with different acid solvents - acetic acid, formic acid, tartaric acid and hydrochloric acid. A portion of the microcapsules was air-dried at ambient temperature while the remaining portion was freeze-dried. The elution of protein from the microcapsules in simulated gastric fluid was monitored spectrophotometrically at $\lambda_{\max } 280$ $\mathrm{nm}$. Results: Tartaric acid effected the highest mean protein retention (54\%) after $9 \mathrm{~h}$ followed by acetic acid (35\%), hydrochloric acid (31\%) and formic acid, (30\%). There appears to be a link between the $p K_{a}$ of the acids and the degree of chitosan-solvent interaction on the one hand, and protein retention on the other hand. Increase in elution $\mathrm{pH}$ from 1.2 to 5.0 did not significantly $(P>0.05)$ affect protein retention. Furthermore, there was no significant difference $(p>0.05)$ between the protein retention capacities of air-dried and freeze-dried microcapsules as both types showed protein retention of $50 \%$ after $5 \mathrm{~h}$.

Conclusion: Tartaric acid was the most suitable solvent for enhancing protein retention in chitosan-alginate microcapsules in simulated gastric fluid.
\end{abstract}

Keywords: Tartaric acid, chitosan, solvent type, microcapsules, air-drying, freeze-drying.

*Corresponding Author: Tel: +234-(0)8037269910, Fax: +234-(0)52-602370 Email: okhamafe@uniben.edu 


\section{Ahonkhai et al}

\section{Introduction}

Membrane coating is applied to solid dosage forms for a variety of reasons, including aesthetics ${ }^{1}$, protection of drug from acid and enzymes in the gut ${ }^{2}$, and environmental degradation ${ }^{3}$, controlled drug release and sitespecific delivery ${ }^{4}$. The choice of solvent in the preparation of coating solution is of particular importance because it affects the physicochemical characteristics of the encapsulating membrane and hence the final drug product. Polymer membrane parameters such as permeability, solubility and stability ${ }^{3}$ as well as microcapsule properties such as size, swelling and drug release profile ${ }^{5}$ have been reported to be influenced by the nature of the solvent used. Among the solvent properties that play a role in this regard are: viscosity, dielectric constant, polarity and $\mathrm{pH}^{3,5 \& 6}$. In the food and drug industry, the final choice of solvent used is usually based on cost, source, availability and toxicity or safety profile of the solvent ${ }^{1}$, which is often a part (even in residual amounts) of the final product.

Chitosan is a naturally occurring polycationic polymer obtained from the $\mathrm{N}$-deacetylation of chitin, found in the exoskeleton of crustaceans and insects ${ }^{6}$. It is freely available, cheap and has antifungal and bacteriostatic properties. Furthermore, because it is easily biodegradable, biocompatible and has great ease of chemical modification $^{7}$, it has found a wide range of applications in pharmacy and medicine such as inhibition of tumor cells, acceleration of wound healing and reduction of blood cholesterol level ${ }^{8}$. It has also been investigated as a suitable polymer coating for oral delivery of proteins/peptide drugs ${ }^{2,}, 4-6$ as well as immobilization/delivery of living cells ${ }^{9}$ \& 10 . Chitosan is insoluble in aqueous, alkali and organic solvents. However, it is soluble in acid solutions when the $\mathrm{pH}$ is less than 6.0. Acetic acid and to a lesser extent, formic acid, are often commonly used for preparing chitosan solutions for encapsulation processes ${ }^{5-7}$.
Drying is usually one of the final processes in drug production and is designed to yield a stable homogeneous product, which is easy to process in subsequent operations of packaging. Some examples of drying methods include freezedrying; spray-drying, fluidized-bed drying, ovendrying and air-drying. The choice of drying method and equipment often depends on the heat sensitivity of the product, the physical characteristics prior to drying, the nature of solvent to be removed and the need for asepsis. The type of drying method employed may affect the properties of the final product ${ }^{11}$.

The objective of this work is to study the effect of the type of acid solvent used in dissolving chitosan as well as drying method on the protein retention capacity of chitosan-alginate microcapsules. The solvents assessed are acetic acid, formic acid, hydrochloric acid and tartaric acid while the two drying methods evaluated were air-drying (at ambient temperature) and freeze-drying.

\section{Materials and Method Materials}

Sodium alginate (Kelco. Chicago IL) and chitosan (medium viscosity grade, Ransom Chem. Co., Redmond, WA) were the polymers used for microcapsule preparation. Bovine serum albumin (BSA) (used as a model protein) was obtained from Fluka AG Chem, Fabrik, Germany. Calcium chloride dihydrate and hydrochloric acid were obtained from $\mathrm{BDH}$ Chemicals, Toronto, Canada. All other chemicals used were of reagent grade.

\section{Method \\ Preparation of encapsulation solutions}

Chitosan solution $(0.1 \%)$ was prepared by dissolving $1 \mathrm{~g}$ of chitosan in $900 \mathrm{ml}$ of distilled water containing $10 \mathrm{ml}$ of glacial acetic acid with the aid of a magnetic stirrer. The molecular weight of the polymer, and hence the viscosity of its solution, were reduced by digesting overnight with $2.14 \mathrm{ml}$ of $1 \% \mathrm{w} / \mathrm{v}$ sodium nitrite solution, i.e., based on a ratio of 0.05 mole sodium nitrite to 1.0 mole chitosan ${ }^{6} .20 \mathrm{~g}$ of calcium chloride dihydrate was dissolved in the solution, $0.2 \mathrm{ml}$ 
polysorbate was added (Tween 80 ) and its $\mathrm{pH}$ was adjusted to 5.5, using sodium hydroxide pellets and solution. The chitosan solution was then filtered and the volume adjusted to $1000 \mathrm{ml}$ with distilled water. This foregoing procedure was repeated using formic acid, hydrochloric acid or tartaric acid in place of glacial acetic acid, except that the final $\mathrm{pH}$ was as follows; formic acid (5.85), hydrochloric acid (2.35) and tartaric acid (2.78). These represent, in each case, the maximum $\mathrm{pH}$ for chitosan solubility beyond which precipitation occurred.

$2.0 \% \mathrm{w} / \mathrm{v}$ sodium alginate solution was prepared by dissolving $2.0 \mathrm{~g}$ of sodium alginate in distilled water using a magnetic stirrer. The volume was then adjusted to $100 \mathrm{ml}$.

\section{Microencapsulation of BSA}

$10 \mathrm{ml}$ of sodium alginate solution containing $2.5 \%$ BSA was extruded into $70 \mathrm{ml}$ of chitosan solution in a glass Petri dish from a $50 \mathrm{ml}$ burette with a $1 \mathrm{~mm}$ diameter orifice. The extrusion distance, i.e., the distance between the burette tip and the surface of the chitosan solution, was fixed at $10 \mathrm{~cm}$. On reaction with calcium ions $\left(\mathrm{Ca}^{2+}\right)$ in the chitosan solution, the polyanionic sodium alginate droplets gel into calcium alginate beads, which then rapidly react with the polycationic chitosan. The resulting microcapsules were allowed an additional reaction time of 2 min following the termination of alginate extrusion, and then examined for size and shape consistency. The microcapsules were harvested by filtration using a nylon megh filter of $0.25 \mathrm{~mm}$ aperture size, washed twice with distilled water and then further rinsed quickly with isopropyl alcohol to remove as much water as possible. Approximately half of the microcapsules produced were dried using a freeze-dryer (Edwards Modulyo, England) at $20^{\circ} \mathrm{C}$ and $608 \mathrm{mmHg}$ for $3 \mathrm{~h}$. The other half of wet microcapsules was air-dried in the laboratory for $24 \mathrm{~h}$ and conditioned over calcium sulphate granules (Drierite ${ }^{(R)}$ ) in a desiccator overnight.

\section{Protein retention studies}

About $200 \mathrm{mg}$ dried microcapsules, accurately weighed, was placed in each of $300 \mathrm{ml}$ wide- mouthed bottles in a thermostated shaker bath (Gallenkamp) set at $30+0.5^{\circ} \mathrm{C} .200 \mathrm{ml}$ of the elution fluid, i.e., $0.1 \mathrm{M} \mathrm{HCL}(\mathrm{pH} 1.2)$ was put in each of the bottles and capped. The shaker bath was agitated at a speed of $80 \mathrm{rpm}$ and elution of BSA from the microcapsules was followed spectrophotometrically using Cecil CE 202 UV/Visible spectrophotometer, Series 2 at $\lambda_{\max } 280 \mathrm{~nm}$. Protein retention was calculated as the difference between the microcapsule protein content prior to elution and the protein released after elution. All tests were carried out in quadruplicate. Assay of the microcapsules for the initial BSA content (load) was also carried out spectrophotometrically at $280 \mathrm{~nm}$. $50 \mathrm{mg}$ of the microcapsules was 'citrated' by dispersing in $20 \mathrm{ml}$ of $0.5 \mathrm{M}$ sodium citrate in scintillation vial and kept overnight. (Citration is used to break down the gel structure containing the entrapped $\operatorname{protein}^{6}$ ). The microcapsules, together with the citrate solution, were then transferred to a mortar and crushed with a pestle to effect maximum $B S A$ release into solution.

\section{Results}

The effect of different acid solutions and drying methods on protein retention in chitosan-alginate microcapsules is shown in Figs 1-3. At $\mathrm{pH} 1.2$ (see Fig. 1), mean protein retention in microcapsules prepared with tartaric acid solution was $54 \%$ after $9 \mathrm{~h}$ compared to $35 \%$ for acetic acid, 31\% for hydrochloric acid and 30\% for formic acid over the same period. The effect of tartaric acid used in preparing chitosan solution on protein retention was found to be significantly different $(p<0.05)$ from those prepared with other acids. When the $\mathrm{pH}$ of the release medium was increased to 5.0 (Fig. 2), there was a decrease in protein retention in all the microcapsules; tartaric acid had protein retention of $38 \%$ after $9 \mathrm{~h}$, followed by microcapsules produced with formic acid, $36 \%$; acetic acid solution had protein retention of $31 \%$; and hydrochloric acid, $23 \%$. Thus, there was no significant difference $(p>0.05)$ in protein retention among the various acids used at $\mathrm{pH}$ 5.0.

Protein retention was similar for both the freezedried and air-dried microcapsules (Fig. 3) as 


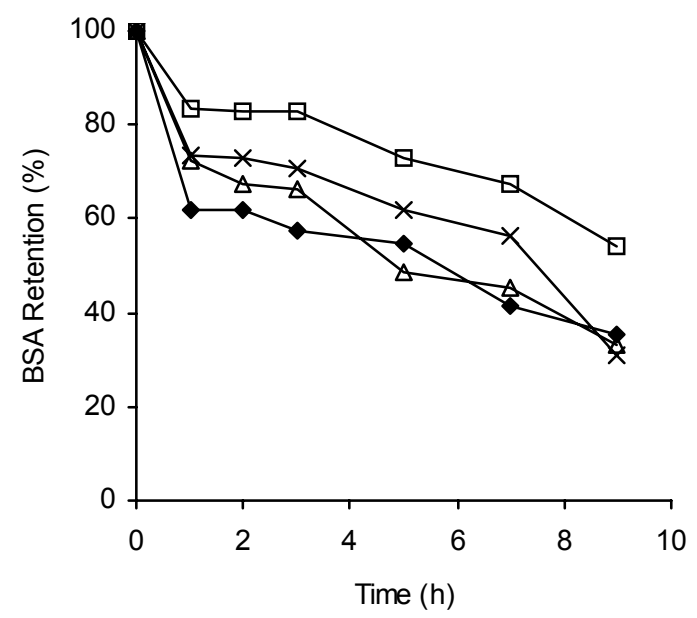

Fig. 1: BSA retention at $\mathrm{pH} 1.2$ in unmodified chitosanalginate microcapsules formulated with chitosan dissolved in solutions of various acids. (Key: acetic acid [^], formic acid $[\Delta]$, tartaric acid $[\square]$ and hydrochloric acid $[\mathrm{x}]$ ).

both groups of microcapsules had approximately $50 \%$ protein retained after $5 \mathrm{~h}$, and $32 \%$ and $37 \%$, protein retained for freeze-dried and airdried microcapsules, respectively, after $9 \mathrm{~h}$.

\section{Discussion \\ Effect of chitosan solvent type and elution pH}

Unmodified chitosan-alginate microcapsules have earlier been reported to be inadequate in retaining proteins in simulated gastric conditions $^{12}$. In that work, acetic acid was used as the chitosan solvent. The findings from the present study show that the protein retention capacity of chitosan-alginate microcapsules may be influenced by the choice of chitosan solvent. A switch from acetic acid to tartaric acid led to enhancement of protein retention from $35 \%$ to $54 \%$. One factor that probably played a role here is the nature and degree of interaction between the solvent and chitosan. The greater the interaction between chitosan and solvent, the more compact and less porous the membrane. Acetic acid, with a $\mathrm{pK}_{\mathrm{a}}$ of 4.76 , is less ionized in aqueous solution than tartaric acid which is a diprotic acid $\left(\mathrm{pK}_{\mathrm{a}} 2.8\right.$ and 4.3 for the two detachable hydrogen ions, respectively). Furthermore, tartaric acid, being diprotic, manifests two carboxyl ( $\left.\mathrm{COO}^{-}\right)$sites compared with one anionic site each for the other acids used. A combination of the two foregoing factors will result in enhanced chitosan-tartaric acid interaction (since chitosan is cationic) and hence a more compact and/or less porous membrane. The consequence is higher protein retention capacity arising from reduced protein diffusion from the microcapsules. Another contributory factor may be deduced from a recent study, which attributed the poor protein retention capacity of unmodified chitosan-alginate microcapsules in $\mathrm{pH} 1.2$ medium to rapid dissolution of the chitosan membrane leading to rapid protein elution from the exposed alginate core $^{12}$. It is likely that the chitosan membrane formed with the tartaric acid, being more compact, stronger and less porous, is less susceptible to acid-induced dissolution at $\mathrm{pH} 1.2$ and, therefore, demonstrated a higher capacity to slow down protein elution from the alginate core than the chitosan membrane formed with acetic acid.

$\mathrm{HCl}$, being completely ionized in water, unlike the other acids used, would ordinarily have been expected to interact most strongly with the cationic chitosan via its $\mathrm{Cl}^{-}$resulting in the most compact and least porous membrane, and hence the highest protein retention. The fact that this is not the case may be due to the inorganic character of $\mathrm{Cl}^{-}$which is not only mobile but lacks the hydrocarbon backbone of the organic anions.

Interestingly, tartaric acid seemed to have lost a significant portion of its effect on protein retention in $\mathrm{pH} 5$ elution medium. In fact, statistical analysis showed that there was no significant difference $(p>0.05)$ in the protein retention capacity of the microcapsules prepared with the four acid solvents. The reason for this is not immediately clear. However, earlier studies ${ }^{5}$ indicate that at $\geq \mathrm{pH} 3$ elution fluid, chitosan membrane remains largely uneroded (undissolved) unlike at $\mathrm{pH}$ 1.2. Thus the membrane pores, protein diffusivity across the chitosan-alginate interface as well as the rate of 
protein transport through the diffusion pathways of the alginate matrix itself would determine the level of protein retention. The relative impact of these three factors (membrane pores, diffusion across the alginate-chitosan interface and diffusivity through the alginate core) could not be determined.

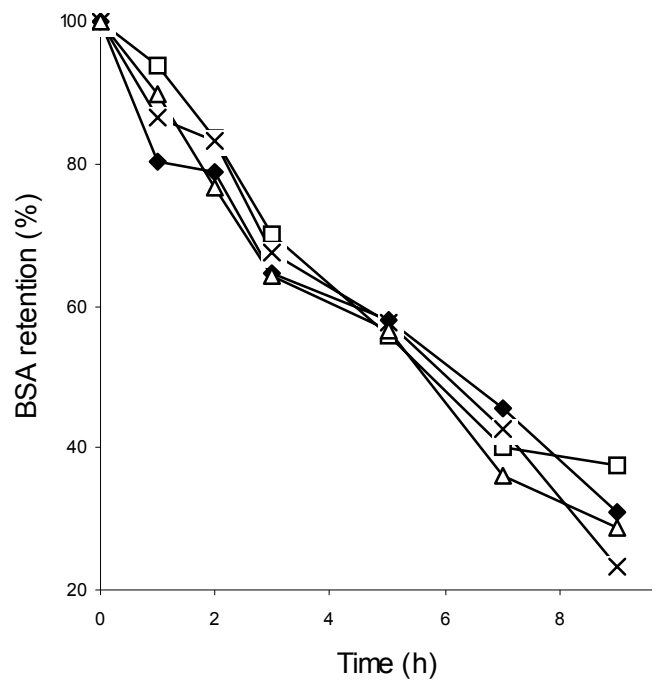

Fig.2: BSA retention in unmodified chitosanalginate microcapsules at $\mathrm{pH} 5$ formulated with chitosan dissolved in solutions of various acids. (Key: acetic acid [ $\bullet]$, formic acid [ $\Delta$ ], tartaric acid $[\square]$ and hydrochloric acid $[\mathrm{X}]$ ).

\section{Effect of drying}

After drying, the microcapsules reduced to about one-third their original size. Freeze-drying was faster (about $3 \mathrm{~h}$ ) than air-drying at ambient temperature (over $24 \mathrm{~h}$ ). However, the release profiles for both the freeze-dried microcapsules and the air-dried microcapsules were similar. It would appear that the drying method used did not exert any structural, molecular and/or morphological effects on the microcapsules that would be irreversible when the dry microcapsules were rehydrated in elution medium.

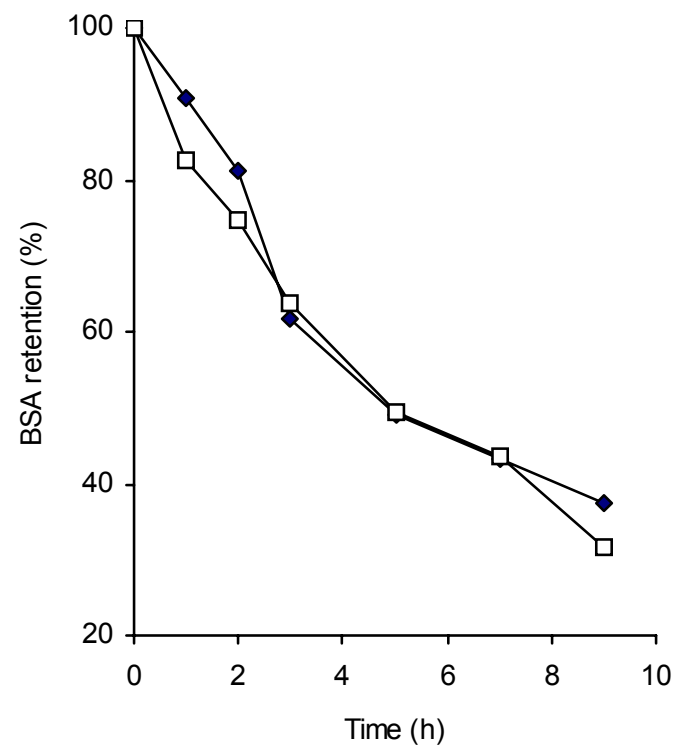

Fig. 3: Effect of drying method on BSA retention from chitosan-alginate microcapsules at pH 1.2. (Key: air-dried [ $\mathbf{\Lambda}]$, freeze-dried $[\square]$ )

\section{Conclusion}

Microcapsules produced with chitosan solution of tartaric acid had better protein retention than those produced using chitosan solutions of acetic acid, formic acid and hydrochloric acid, respectively. When the elution $\mathrm{pH}$ was raised from 1.2 to 5.0 , there was no significant change $(p>0.05)$ in protein retention except for microcapsules prepared with chitosan dissolved in tartaric acid, which showed a drop in protein retention. It was also observed that the drying method used (air-drying or freeze-drying) did not affect the rate of protein elution from chitosan-alginate microcapsules.

\section{References}

1. Deasy PB. Microencapsulation and Related Drug Processes. Drug and Pharmaceutical Science Series. In: Deasy PB (Ed). Marcel Dekker Inc. 1984; 20.

2. Arhewoh IM, Ahonkhai El and Okhamafe AO. Optimising Oral Systems for the Delivery of Therapeutic Proteins and Peptides. Afr J Biotech. 2005; 4(13): 1591-1597.

3. Okhamafe AO and Goosen MFA. Control of Membrane Permeability in Microcapsules. In; Fundamentals of Animal Cell Encapsulation and Immobilization. 


\section{Ahonkhai et al}

Goosen MFA (Ed) CRC Press, Inc. USA. 1993; 5578.

4. Arhewoh IM and Okhamafe AO. An Overview of SiteSpecific Delivery of Orally Administered Proteins/Peptides and Modelling Considerations. J Med Biomed Res. 2004; 3(1) 7-20.

5. Polk A, Amsden B, De Yao K, Peng $T$ and Goosen MFA. Controlled Release of Albumin from Chitosan-alginate Microcapsules. J. Pharm. Sci. 1994; 83(2): 178-185.

6. McKnight CA, Ku A, Goosen MFA, Sun D and Penny $C$. Synthesis of Chitosan-alginate Microcapsule Membrane. J Bioact and Compat Polym. 1988; 3: 335-354.

7. Allan GG, Altman LC, Bensinger RE, Ghosh DK, Hirabayashi Y, Neogi AN and Neogi S. Biomedical Applications of Chitin and Chitosan. In: Chitin, Chitosan and Related Enzymes. J P Zikakis (Ed) Academic Press. Inc. 1984; 119 - 133.
8. Dunn QL, Sugita ET, Grandmaison EW and Goosen MFA. Applications and Properties of Chitosan. J Bioact and Compat Polym. 1992; 7: 371-397.

9. Okhamafe AO and Goosen MFA. (1999). Modulation of Membrane Permeability. In; Cell Encapsulation Technology and Therapeutics. Goosen Mattheus (Ed) Birkhäuser Boston, USA. 1999; 53-62.

10. Takechi $H$, Yamamoto $H$, Niwa $T$, Hinos $T$ and Kawashima Y. Enteral Absorption of Insulin in Rats from Mucoadhesive Chitosan-coated Liposome. Pharm. Res.1996; 13: 896 - 901

11. Rawlins EA. Bentley's Textbook of Pharmaceutics. $\left(8^{\text {th }}\right.$ edition) Bailliere Tindall (1977). 186.

12. Okhamafe AO, Amsden B, Chu $W$ and Goosen MFA. Modulation of Protein Release from Chitosanalginate Microcapsules Modified with the $\mathrm{pH}$ Sensitive Polymer - Hydroxylpropyl Methylcellulose Acetate Succinate (HPMCAS). J Microencapsul. 1996; 13: 497-508 